\title{
A Retrospective Descriptive Study of Adverse Drug Reaction Monitoring in Tertiary Care Hospital
}

\author{
Ajay K Gupta
}

\begin{abstract}
Introduction: An adverse drug reaction (ADR) is any undesirable effect of a drug to the patient beyond its anticipated therapeutic effects while used clinically.

Aims and objective: To analyze the incidence of ADRs in a tertiary care hospital reported from April 2015 till December 2017.

Materials and methods: Two hundred ADR forms were included in the study and analyzed. These were codified into various drug classes according to anatomical therapeutic chemical (ATC) classification based on WHO-ATC Index 2019 besides categorized into preventable or not modified Schumock and Thornton scale. Severity was assessed based on a scale by Hartwig et al. Also, the ADRs were classified based on MedDRA 13.01 to system organ class (SOC) and preferred terms (PT) falling under respective SOC.

Results: Maximum ADRs were reported by dermatology. Most commonly, it involved gastrointestinal system (GIT) followed by skin. Antibiotics and anti-cancer drugs caused maximum ADRs. About two-thirds were classifiable as moderate to severe, whereas about one-third were preventable. About $10 \%$ of cases were such that left deep impact of sequelae or were not recovered and one case was fatal.

Conclusion: Extreme vigilance by clinicians is of utmost crucial virtue in detecting, diagnosing, and reporting such ADR for continued drug safety monitoring.

Keywords: Adverse drug reaction, Pharmacovigilance, Safety monitoring.

Journal of Medical Academics (2020): 10.5005/jp-journals-10070-0061
\end{abstract}

\section{INTRODUCTION}

Medical practice initiates the use of drugs by healthcare deliverers to achieve a therapeutic goal with a noble intention of the benefit to the patients in the form of relief of symptoms, minimizing disease progression or prevention of diseases, and thus improve quality of life (QoL); however, interventions attempted can never be guaranteed besides adverse drug reactions (ADRs) if not as a rule are common in medical practices. When a drug is marketed its safety is not much understood being used on limited no. of subjects but only in clinical use after a large population is exposed, the ADRs are known. Adverse drug reaction is defined as any noxious and unintended response to the use of a drug/therapeutic agent that occurs at a dose used normally in human beings for prophylaxis, diagnosis, therapy, or modifying the physiological system to the benefit of the recipient. In modern-day clinical practice, ADRs are an important and leading cause of morbidity and mortality which is one of the most important factors for healthcare-related major economic burden. The ADR reporting rate is below $1 \%$ in India compared to the worldwide rate of $6-10 \% .^{2}$ Adverse drug reactions are known to cause no $<6 \%$ of hospital admissions of the patients which constitute around $6-15 \%$ of hospitalized patients and about 3.7\% have fatal ADRs. ${ }^{3}$ Thus, systematic reporting and assessments of ADRs by Adverse Drug Reaction Monitoring Centres (AMCs) has become a need of time in present-day medical practice to safeguard the health of patients globally. ${ }^{4}$ Such ADR reporting programs encourage surveillance for ADRs, promote the reporting of ADRs by all stakeholders in healthcare delivery including now by the paramedics and patients too to develop robust, and proven data that help in the education of health professionals regarding potential ADRs. ${ }^{5}$

In the year 1968, WHO took the initiative of safeguarding the health of the public at large following the Thalidomide tragedy.
Department of Pharmacology, Army College of Medical Sciences, Delhi, India

Corresponding Author: Ajay K Gupta, Department of Pharmacology, Army College of Medical Sciences, Delhi, India, Phone: +91 9765090428, e-mail: ajayneera2007@rediffmail.com

How to cite this article: Gupta AK. A Retrospective Descriptive Study of Adverse Drug Reaction Monitoring in Tertiary Care Hospital. J Med Acad 2020;3(2):54-58.

Source of support: Nil

Conflict of interest: None

Hence, Uppsala Monitoring Centre was established in Sweden which maintains an international database of ADRs reported from all National Coordinating Centre (NCC) across the globe. India too joined the program and started its Pharmacovigilance program in 1982 having it at AlIMS, Delhi. However, due to under-reporting of ADRs as is pan existing in other parts of the world the same could not continue but was re-started and finally is successfully functioning with its headquarter at Ghaziabad, UP. In India, the nationwide program is known as Pharmacovigilance Programme of India (PvPI) which is operating as NCC at headquarter and gets inputs from pan India AMCs. All AMCs are uploading data using vigiflow software which is integrated and ratified for causality assessment at NCC and further uploaded to the global vigiflow database.

Pharmacovigilance is the branch of science entrusted with data collection about drug usage and analysis on the observed adverse events in its use in the large population. This practice is in with the foresight to improve the safe and rational practice of drug usage. Periodic analyzes of ADRs due to existing drugs and also newer drugs help in characterizing the pattern of ADRs and thereby help 
regulatory bodies in implementing steps to improve the drug safety in the working set up of the healthcare delivery institutions. Safer and better healthcare practice could only be ensured by applying this knowledge about ADRs when the population at large receives the same much beyond the close confines of few patients in phase 3 of drug development. ${ }^{6}$ Data generated from such structured and periodic monitoring about ADRs further contributes to initially the national and finally to international databases on ADRs which ultimately contributes to drug safety decisions and may serve as a basis for product labeling, ${ }^{7}$ revision, and design patient education strategies. In the direction of the safe use of drugs initiative by the Govt of India (Gol) via the national program on the issue known as PvPI, medical colleges have been made part of this national movement and designated as AMC. With this noble start of this AMC, data are collated from the affiliated tertiary care hospital affiliated to the college wherein an attempt is made to monitor ADRs by analyzing and further reported to NCC.

\section{Materials and Methods}

Suspected ADR reporting forms formulated by Central Drugs Standard Control Organization (CDSCO) was utilized by healthcare stakeholders of affiliated tertiary care hospital of the college which were included in for analysis. Two hundred such reported ADR forms were collected from all OPDs and in-patients admitted to the hospital which was analyzed for causality and further uploaded to NCC using vigibase software from April 2015 till December 2017 which were taken in this descriptive study. Data on the reported ADRs were evaluated to understand the pattern of the ADRs with respect to patient demographics, nature of the reactions, characteristics of the drugs involved. Also, data were analyzed for causality, severity, the preventability of the adverse reactions. Prior permission was taken from the Institutional Ethics Committee of the college.

Patients of both sex and all age group were considered in this retrospective study whose ADR forms were valid based on CDSCO criteria of the information reported by the reporter. The data were analyzed by grouping patients into four age groups; children (0-12 years), young adults (13-30 years), adults (31-60 years), elderly ( $>60$ years). Drugs involved in the ADRs were codified into various drug classes according to anatomical therapeutic chemical (ATC) ${ }^{8}$ classification based on WHO-ATC Index 2019. To assess the likelihood that drugs have caused the reaction, causality assessment was done using WHO Uppsala monitoring center (UMC) probability scale whereby the ADR outcomes were classified into designated categories like-certain, probable/likely, possible, unlikely, conditional/unclassified, and unassessable/unclassifiable to be drug suspected depending upon the level of association. Further data were also analyzed for predictability based on Aronson classification as below:

Type I-augmented, dose-related.

Type II-bizarre, non-dose related.

Type III-chronic, dose, and time-related.

Type IV—delayed, time-related.

Type $\mathrm{V}$-end of use, withdrawal reactions.

Type VI-failure of therapy.

In the study, type II was considered as unpredictable, and the rest all, i.e., type I, III, IV, V, VI as predictable.

Adverse drug reactions were also categorized into preventable or not using the criteria of the modified Schumock and Thornton scale. ${ }^{9}$
Questionnaire if the ADR was preventable

Definitely preventable

1. Was there a history of allergy or a previous reaction to the drug?

2. Was the drug involved inappropriate for the patient?

3. Was the route, frequency, or dose administered inappropriate for the patients' age weight or disease?

4. Was a toxic serum drug (or a laboratory monitoring test) documented?

5. Was there a known treatment for the adverse drug reaction?

Probably preventable

6 . Was required therapeutic drug monitoring or other necessary laboratory test not performed?

7. Was a potential drug interaction involved in ADR?

8. Was poor compliance involved in the ADR?

9. Were preventive measures not prescribed or administered to the patient?

Not preventable

10. If all the above criteria are not fulfilled?

Answers to questions 1-9 as "yes" were taken as the ADR might have been preventable. Further, ADRs were classified into mild, moderate, and severe reactions using the criterion ${ }^{4}$ developed by Hartwig et al. for severity assessment.

\begin{tabular}{|c|c|}
\hline Level & Description \\
\hline 1 & $\begin{array}{l}\text { The ADR requires no change in treatment with the sus- } \\
\text { pected drug. }\end{array}$ \\
\hline 2 & $\begin{array}{l}\text { The ADR requires the suspected drug to be withheld, } \\
\text { discontinued, or otherwise changed. No antidote or other } \\
\text { treatment is required. There is no increase in the length of } \\
\text { stay in the hospital. }\end{array}$ \\
\hline 3 & $\begin{array}{l}\text { The ADR requires that the suspected drug be withheld, } \\
\text { discontinued, or otherwise changed, and/or an antidote } \\
\text { or another treatment is required. There is no increase in } \\
\text { the length of hospital stay. }\end{array}$ \\
\hline 4 & $\begin{array}{l}\text { Level } 4 a \text {-any level } 3 \text { ADR that increases the length of } \\
\text { hospital stay by at least } 1 \text { day. }\end{array}$ \\
\hline \multicolumn{2}{|c|}{ Level $4 b$ —the ADR is the reason for admission. } \\
\hline 5 & Any level 4 ADR that requires intensive medical care. \\
\hline 6 & The ADR causes permanent harm to the patient. \\
\hline 7 & $\begin{array}{l}\text { The ADR either directly or indirectly leads to the death of } \\
\text { the patient. }\end{array}$ \\
\hline
\end{tabular}

Severity level: mild $-1,2$; moderate-3, 4; Severe $-5-7$

\section{Results}

Two hundred ADR forms from all OPDs and the indoor patients which were collected/reported during the period of study were analyzed, the majority of them were from the Department of Dermatology, Oncology and Pediatrics. Upon evaluation, the majority of ADRs were reported in males (59.3\%). According to age, we found ADR frequency as-children (16.5\%), young adults (12.5\%), adults (37.5\%), and old (18\%).

As per the classification based on MedDRA 13.01, the ADRs were classified according to system organ class (SOC) and preferred terms (PT) falling under respective SOC using. The most commonly affected SOC was gastrointestinal (42\%), followed by skin and subcutaneous tissue disorder (33.8\%) whereas the minimal was from renal and ENT issues (Table 1). 
Table 1: Classification* according to system organ class (SOC) and preferred terms (PT) falling under respective SOC using MedDRA 13.0 Version English

\begin{tabular}{|c|c|c|c|}
\hline SOC & $\begin{array}{l}\text { ADR reports } \\
(\%)(n=200)\end{array}$ & $\begin{array}{l}\text { Preferred terms } \\
\text { (PT) }\end{array}$ & $\begin{array}{l}\text { ADR reports } \\
\text { (\%) }\end{array}$ \\
\hline \multirow{7}{*}{$\begin{array}{l}\text { Gastrointestinal } \\
\text { disorder }\end{array}$} & $74(37)$ & Vomiting & $33(44.6)$ \\
\hline & & Diarrhea & $18(24.3)$ \\
\hline & & Nausea & $6(8.1)$ \\
\hline & & Hematemesis & $5(6.8)$ \\
\hline & & $\begin{array}{l}\text { Gingival } \\
\text { hypertrophy }\end{array}$ & $4(5.4)$ \\
\hline & & Abdominal pain & $4(5.4)$ \\
\hline & & Mouth ulcerations & $4(5.4)$ \\
\hline \multirow{6}{*}{$\begin{array}{l}\text { Skin and } \\
\text { subcutaneous } \\
\text { tissue disorder }\end{array}$} & $61(30.5)$ & $\begin{array}{l}\text { Rash } \\
\text { maculopapular }\end{array}$ & $19(11.6)$ \\
\hline & & Rash & $13(7.9)$ \\
\hline & & Fixed eruption & $11(6.7)$ \\
\hline & & Urticaria & $9(5.5)$ \\
\hline & & Alopecia & $5(3.1)$ \\
\hline & & Angioedema & $4(2.4)$ \\
\hline $\begin{array}{l}\text { Blood and lymphat- } \\
\text { ic system disorder }\end{array}$ & $32(16)$ & $\begin{array}{l}\text { Bone marrow } \\
\text { failure }\end{array}$ & $32(100)$ \\
\hline $\begin{array}{l}\text { Nervous system } \\
\text { disorders }\end{array}$ & $17(8.5)$ & Ataxia & $17(100)$ \\
\hline $\begin{array}{l}\text { Immune system } \\
\text { disorders }\end{array}$ & $5(2.5)$ & Redman syndrome & $5(100)$ \\
\hline $\begin{array}{l}\text { Hepatobiliary } \\
\text { disorders }\end{array}$ & $4(2)$ & Hepatitis & $4(100)$ \\
\hline $\begin{array}{l}\text { Renal and urinary } \\
\text { disorders }\end{array}$ & $4(2)$ & Hesitancy & $4(100)$ \\
\hline $\begin{array}{l}\text { Ear and labyrinth } \\
\text { disorders }\end{array}$ & $3(1.5)$ & Tinnitus & $3(100)$ \\
\hline
\end{tabular}

Also to mention the ADRs were related to groups of drugs as well which indicated max ADRs were related to usage with anti-neoplastic and antimicrobials use where with the use of antiepileptics and antiemetics/prokinetic group of drugs (Table 2).

Further data were also analyzed for predictability based on Aronson classification of the ADR collected-type I, III, IV, V were $73 \%$ and type II $27 \%$. Most of the type II reactions were hypersensitivity reactions and generally presented as fixed drug reactions or some type of skin lesions/rashes. All the reactions except type II (hypersensitivity) were considered predictable, i.e., $73 \%$.

Upon causality assessment, the majority of the reports were rated as probable (62.6\%) followed by possible (14.5\%).

Modified Hartwig and Siegel scale was used to assess the severity. The majority of reactions 124 (62\%) were of level 1 and 2 (mild) and moderate and severe level reactions accounted for 32.5 and $5.5 \%$ of the reports, respectively (Table 3 ).

The preventability of ADRs was based on Schumock and Thornton scale. Adverse drug reactions were classified into
Table 2: Drug class and individual drugs* - most commonly associated with ADRs

\begin{tabular}{|c|c|c|c|}
\hline $\begin{array}{l}\text { Drug class } \\
\text { (according to the } \\
\text { second level of ATC } \\
\text { classification) }\end{array}$ & $\begin{array}{c}\text { ADR reports, } \\
n=200 \text { (\%) }\end{array}$ & Drug & $\begin{array}{l}A D R \\
\text { reports } \\
\text { (\%) }\end{array}$ \\
\hline \multirow{9}{*}{$\begin{array}{l}\text { Antineoplastic } \\
\text { agents (L01) }\end{array}$} & $87(43.5)$ & Cisplatin & $19(21.8)$ \\
\hline & & $5 \mathrm{FU}$ & 13 (14.9) \\
\hline & & Adriamycin & $12(13.8)$ \\
\hline & & Paclitaxel & $11(12.6)$ \\
\hline & & Etoposide & $10(11.5)$ \\
\hline & & Cyclophosphamide & $10(11.5)$ \\
\hline & & Carboplatin & $9(10.3)$ \\
\hline & & Methotrexate & $2(2.3)$ \\
\hline & & Bleomycin & $1(1.1)$ \\
\hline \multirow{5}{*}{$\begin{array}{l}\text { Antibacterial for } \\
\text { systemic use (J01) }\end{array}$} & $62(31)$ & Vancomycin & $32(51.6)$ \\
\hline & & Cephalosporins & $18(29)$ \\
\hline & & Quinolones & $4(6.5)$ \\
\hline & & Metronidazole & $4(6.5)$ \\
\hline & & Amoxicillin & $4(6.5)$ \\
\hline \multirow[t]{2}{*}{ Antimalarials (PB01) } & $22(11)$ & Chloroquine & $12(54.5)$ \\
\hline & & Quinine & $10(45.5)$ \\
\hline \multirow{4}{*}{$\begin{array}{l}\text { Antimycobacterials } \\
\text { (J04) }\end{array}$} & $9(4.5)$ & Isoniazid & $3(33.3)$ \\
\hline & & Pyrazinamide & $2(22.2)$ \\
\hline & & Rifampicin & $2(22.2)$ \\
\hline & & Ethambutol & $2(22.2)$ \\
\hline $\begin{array}{l}\text { Antithrombotic } \\
\text { agents (B01) }\end{array}$ & $3(1.5)$ & Aspirin & $3(100)$ \\
\hline \multirow{2}{*}{$\begin{array}{l}\text { Ant-inflammatory } \\
\text { and antirheumatic } \\
\text { products (M01) }\end{array}$} & $6(3)$ & Paracetamol & $3(50)$ \\
\hline & & Diclofenac & $3(50)$ \\
\hline Antiepileptic (N03) & $5(2.5)$ & Phenytoin & $5(100)$ \\
\hline $\begin{array}{l}\text { Antiemetics and } \\
\text { antinauseants (A04) }\end{array}$ & $2(1)$ & Metoclopramide & $2(100)$ \\
\hline Miscellaneous & $4(2)$ & & $4(100)$ \\
\hline
\end{tabular}

*Drug class and drug with at least two reports are included

Table 3: Severity of ADRs

\begin{tabular}{lll}
\hline Category & No. of ADRs $(n=200)$ & Percentage \\
\hline Mild (level 1, 2) & 124 & 62 \\
Moderate (level 3, 4) & 65 & 32.5 \\
Severe (level 5, 6, 7) & 11 & 5.5 \\
\hline
\end{tabular}

definitely preventable, probably preventable, and not preventable. The majority seemed to be not preventable (Table 4).

The final outcome of ADRs is as per the data presented in Table 5. Two-thirds of cases approximately recovered without any residual disability with or without medical intervention. About 38 cases at the point of time the reporting ADR was recovering and 8 had not at all recovered. Besides most distressing situation was with seven cases, which though had recovered but with sequelae of ADRs for their life in some form and unfortunately one was fatal. 
Table 4: Preventability of ADRs

\begin{tabular}{lcc}
\hline Category & No. of ADRs $(n=200)$ & Percentage \\
\hline Definitely preventable & 5 & 2.5 \\
Probably preventable & 67 & 33.5 \\
Not preventable & 128 & 64 \\
\hline
\end{tabular}

Table 5: Outcome of ADRs

\begin{tabular}{lcl}
\hline Category & No. of ADRs $(n=200)$ & Percentage \\
\hline Recovered & 146 & 73 \\
Recovering & 38 & 19 \\
Not recovered & 8 & 4 \\
Recovered with sequelae & 7 & 3.5 \\
Fatal & 1 & 0.5 \\
\hline
\end{tabular}

\section{Discussion}

Adverse drug reactions can have a detrimental effect on a patients' well-being ${ }^{3,10}$ and the overall healthcare system also gets overburdened with limited resources. Two hundred ADRs were analyzed which revealed slight gender bias of ADRs to males in comparison to females which is varying from other studies. ${ }^{11}$ Such gender variations in ADRs are likely to happen as it depends on reporting by the healthcare professionals as well as the patients if come forth for reporting of such events to their clinicians or reports themselves. However, yet another study reported slightly higher ADRs in female but finds no significant difference between different age groups. ${ }^{12}$

The present study has brought out that the maximum proportion of ADRs is from the adults' age group, which is in tandem with other studies like Yu et al. ${ }^{13}$ It was noticed in our study to have maximum ADRs having symptoms pertaining to Dermatology in form of mostly rashes, etc., besides others related to oncology and pediatrics which have been so with many other studies as reported world over. ${ }^{14}$ The study brings out the most affected organ system effected during course of ADRs reported were belonging to the gastrointestinal system (GIT) which is same as been reported by other observational studies to by Hakkarainen et al. ${ }^{15-17}$ Commonest group of drugs with the highest most association for ADRs is belonging to antineoplastic drugs followed with AMAs which also is correlating to other studies published..$^{16,17}$

Adverse drug reaction analysis and knowledge are most important when the future potential ADRs are reducible which is preventability of such events. This study has seen to have at least $73 \%$ ADRs which could have been prevented whereas other studies also have a range of 65 to $84 \%$ preventable ADRs. ${ }^{16}$ The ones which are bizarre or non-preventable are generally idiosyncratic reactions which comprised here about $27 \%$ of all the reported ADRs whereas some others have reported this as low as $<5 \%$ even. ${ }^{14}$ Causality assessment is the most important domain of pharmacovigilance and thus improves the predictability of likely ADRs in the future. In the present study, the most common causality that could be justified was probable and the possible which correlates with other studies. $^{18}$

Ahead of any rational study is the severity of all these ADRs which may from the spectrum of as mild as almost unnoticed to as serious as can be prolongations in-hospital stay and even death or permanent residual disability. As in our study, the same has been that majority of ADRs are mild in nature which accounts for two-thirds of almost all ADRs but nearly one-third of them have been moderate to severe even as published in other studies too. ${ }^{19}$ Adverse drug reaction study is most important with the view of decreasing future events of ADRs based on continuous robust data build up and updation of knowledge of clinicians.

In our study, at least about one-third of ADRs were likely preventable as has been reported with studies elsewhere. ${ }^{19}$ Lastly, the study brings out the outcome of the ADRs where it is seen that almost one-third of the subjects did experience the ADRs which had long stay in the hospital as well as left some residual disabilities. Other studies also have reported the incidence of serious and preventable ADRs in the tune of $42 \%$ with about $1 \%$ fatal. ${ }^{20}$

Adverse drug reaction collecting skills in a hospital can help to continuously improve the safety of drug therapies, measure the incidence of ADR rates over a long time, and help educate healthcare professionals of potential drug adverse effects ${ }^{5}$ and increase their level of awareness. Some differences in drug usage patterns in our setup from the settings in which the other studies were conducted could have contributed to the difference in pattern. Such studies enable in obtaining information on the incidence and pattern of ADRs in the local population. Similar reporting programs are necessary to educate and to increase awareness about reporting of ADRs among the healthcare professionals in our country.

\section{Conclusion}

The present study was a descriptive retrospective observational study based on the ADR reports collected during the period of study. Authors' institution is an approved AMC under PvPI and there is a well-established system for reporting, analyzing, and preventing ADRs. The maximum number of meaningful adverse reports on ADR reporting forms that were collected were included and analyzed as precisely as possible. It is imperative that the reporting of ADRs by clinicians is a voluntary practice and there is slackness in reporting of ADRs due to various reasons, there has to be under-reporting of ADRs, considering the number of patients taking treatment from the hospital and the number of drugs dispensed in dispensary and in-patients in wards. The author hopes this study will foster the practice of legitimate reporting among healthcare professionals and all stakeholders as well as patients themselves. The findings from this study should make everyone aware of possibilities of ADRs even when it is least expected, which should always be kept in mind while managing any medical condition, as the fact of ADRs happening has a significant impact on the course of treatment and outcome.

\section{References}

1. Ditto AM. Drug allergy. In: Patterson's Allergic Diseases Grammer LC, Greenberger PA, ed. 6th ed., Philadelphia: Lippincott Williams \& Wilkins; 2002. p. 295.

2. Shajahan J. An analysis of seriousness, predictability and preventability of adverse drug reactions reported at a tertiary care teaching hospital in Kerala, India: a retrospective observational record based study. Int J Basic Clin Pharmacol. 2018;7(12):2433-2438.

3. Lazarou J, Pomeranz BH, Corey PN. Incidence of adverse drug reactions in hospitalized patients: a meta analysis of prospective studies. JAMA 1998;279:1200-1205. DOI: 10.1001/jama.279.15.1200 Yadav S. Status of adverse drug reaction monitoring and pharmacovigilance in selected countries. Indian J Pharmacol 2008;40(Suppl. 1):S4-S9.

4. Hartwig SC, Siegel J, Schneider PJ. Preventability and severity assessment in reporting adverse drug reactions. Am J Hosp Pharm 1992;49(9):2229-2232. DOI: 10.1093/ajhp/49.9.2229. 
5. American Society of Health System Pharmacists. ASHP guidelines on adverse drug reaction monitoring and reporting. Am J Hosp Pharm 1989:46:336-337.

6. Gallelli L, Ferreri G, Colosimo M, et al. Retrospective analysis of adverse drug reactions to bronchodilators observed in two pulmonary divisions of Catanzaro, Italy. Pharmacol Res 2003;47(6):493-499. DOI: 10.1016/S1043-6618(03)00003-3.

7. Wu WK. Evaluation of outpatient adverse drug reactions leading to hospitalization. Am J Health Syst Pharm 2003;60(3):253-259. DOI: 10.1093/ajhp/60.3.253.

8. WHO Collaborating Centre for Drug Statistics Methodology. Completed ATC Index 2005. http://www.whocc.no/atcddd/.

9. Schumock GT, Thornton JP. Focusing on the preventability of adverse drug reactions. Hosp Pharm 1992;27:538.

10. Bates DW, Spell N, Cullen DJ, et al. The cost of adverse drug events in hospitalized patients. JAMA 1997;277(4):307-311. DOI: 10.1001/ jama.1997.03540280045032.

11. Lucca JM, Ramesh M, Ram D. Gender differences in the occurrences and pattern of adverse drug reactions in psychiatric patients: a prospective observational study. Trop J Med Res 2017;20(1):84-90. DOI: 10.4103/1119-0388.198134.

12. Jha N, Bajracharya O, Namgyal T. Prevalence of adverse drug reactions with commonly prescribed drugs in different hospitals of Kathmandu valley. Kathmandu Univ Med J (KUMJ) 2007;5(4): 504-510.
13. Yu YM, Shin WG, Lee JY, et al. Patterns of adverse drug reactions in different age groups: Analysis of spontaneous reports by community pharmacists. PLoS ONE 2015;10(7):e0132916. DOI: 10.1371 journal. pone. 0132916.

14. Lau PM, Stewart K, Dooley M. Support Care Cancer 2004;12:626.

15. Hakkarainen KM, Gyllensten $H$, Jönsson AK, et al. Prevalence, nature and potential preventability of adverse drug events - a populationbased medical record study of 4970 adults. $\mathrm{Br} J$ Clin Pharmacol 78(1):170-183. DOI: 10.1111/bcp.12314.

16. Scheiber J, Jenkins JL, Sukuru SCK, et al. Mapping adverse drug reactions in chemical space. J Med Chem 2009;52(9):3103-3107. DOI: 10.1021/jm801546k.

17. Chan SL, Ang X, Sani LL, et al. Prevalence and characteristics of adverse drug reactions at admission to hospital: a prospective observational study. Br J Clin Pharmacol 2016;82(6):1636-1646. DOI: 10.1111/bcp.13081.

18. Varallo FR, Planeta CS, Herdeiro MT, et al. Imputation of adverse drug reactions: causality assessment in hospitals. PLoS ONE 2017;12(2):e0171470. DOI: 10.1371/journal.pone.0171470.

19. Padmavathi S, Manimekalai K, Ambujam S, et al. Causality, severity and preventability assessment of adverse cutaneous drug reaction: a prospective observational study in a tertiary care hospital. J Clin Diagnos Res: JCDR 2013;7(12):2765-2767.

20. Bates DW, Cullen DJ, Laird N, et al. Incidence of adverse drug events and potential adverse drug events: implications for prevention. JAMA 1995;274(1):29-34. DOI: 10.1001/jama.1995.03530010043033. 